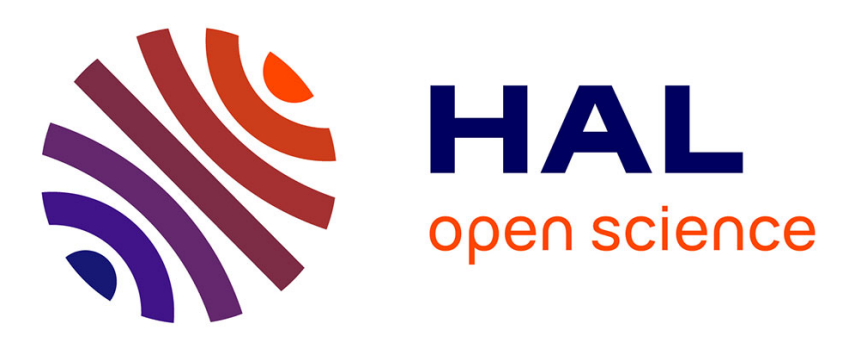

\title{
Effects of Short- and Long-Term Unemployment on Health Satisfaction: Evidence from German Data. Laura Romeu Gordo
}

\section{To cite this version:}

Laura Romeu Gordo. Effects of Short- and Long-Term Unemployment on Health Satisfaction: Evidence from German Data.. Applied Economics, 2006, 38 (20), pp.2335-2350. 10.1080/00036840500427692 . hal-00581914

\section{HAL Id: hal-00581914 \\ https://hal.science/hal-00581914}

Submitted on 1 Apr 2011

HAL is a multi-disciplinary open access archive for the deposit and dissemination of scientific research documents, whether they are published or not. The documents may come from teaching and research institutions in France or abroad, or from public or private research centers.
L'archive ouverte pluridisciplinaire HAL, est destinée au dépôt et à la diffusion de documents scientifiques de niveau recherche, publiés ou non, émanant des établissements d'enseignement et de recherche français ou étrangers, des laboratoires publics ou privés. 


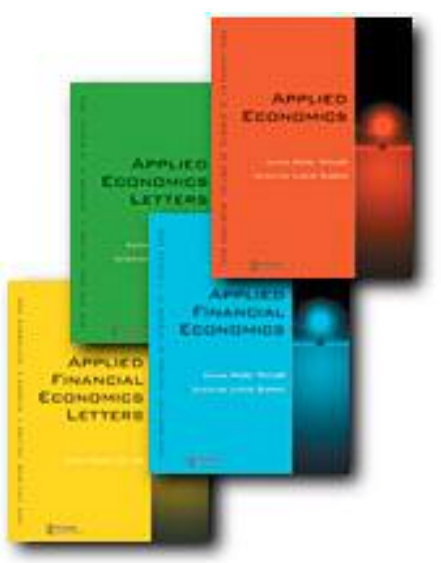

Effects of Short- and Long-Term Unemployment on Health Satisfaction: Evidence from German Data.

\begin{tabular}{|r|l|}
\hline Journal: & Applied Economics \\
\hline Manuscript ID: & APE-05-0117.R1 \\
\hline Journal Selection: & Applied Economics \\
\hline $\begin{array}{r}\text { Date Submitted by the } \\
\text { Author: }\end{array}$ & 22-Sep-2005 \\
\hline JEL Code: & $\begin{array}{l}\text { I10 - General < , J21 - Labor Force and Employment, Size, and } \\
\text { Structure < }\end{array}$ \\
\hline Keywords: & $\begin{array}{l}\text { Health satisfaction, Short- and long-term unemployment, } \\
\text { Reemployment, Longitudinal data }\end{array}$ \\
\hline \multicolumn{2}{|l}{} \\
\hline
\end{tabular}




\title{
Effects of Short- and Long-Term Unemployment on Health Satisfaction: Evidence from German Data.
}

\begin{abstract}
The purpose of this paper is to analyse the effects of short- and long-term unemployment on health satisfaction. The data source used for the analysis is the German Socio-Economic Panel (GSOEP) which, given its longitudinal structure, allows us to better overcome the problem of endogeneity.

Three different models are used in order to assess the effect of short and long-term unemployment and reemployment on health satisfaction. The results show that short-term unemployment has only a significant (and negative) effect for men, while for women, short-term unemployment does not have a significant effect on health satisfaction. Being unemployed for a long period has a significant and negative effect for both men and women. Finally, it can be also concluded from our empirical analysis that reemployment has a significant and positive effect on health satisfaction for both unemployed men and women, independent of how long individuals have been unemployed.
\end{abstract}




\section{Introduction}

Unemployment rates have been increasing in Germany in recent years. The rate of registered unemployment in 1988 was $6.2 \%{ }^{1}$ while in 2001 it was $10.0 \%{ }^{2}$.

This tendency is not changing. In January 2005 the unemployment rate was $12.1 \%$, which represents an increase of $11 \%^{3}$ with respect to January of last year. Therefore, unemployment and policies aimed at reducing these increasing rates have become one of the main concerns of the German government.

One of the factors that is contributing to the present situation in the German labour market is the current unfavourable macroeconomic situation. However, there is consensus about the necessity of carrying out structural reforms of the German labour market. One of the aspects of the present situation that is frequently criticized is the excessive protection offered by the state to individuals who remain unemployed for long periods. The argument is that due to the long duration of the financial support that unemployed people receive, individuals do not feel under pressure to find a new job immediately after losing their previous job. As a result, the period of unemployment increases, and this leads to undesirable rates of longterm unemployment. According to this argument, a reduction in the period to which individuals are entitled to financial support would have positive effects on reemployment.

In this context, the German government has proposed reducing the maximal duration of the period during which individuals have the right to receive unemployment benefits. These measures are designed to incentivize the search for a job in order to avoid long-term unemployment.

\footnotetext{
${ }^{1}$ Source: EUROSTAT.

2 Source : LABORSTA (Labour statistics database operated by the ILO Bureau of Statistics).

${ }^{3}$ Source: Bundesagentur für Arbeit.
} 
However, although measures that incentivize job search may be effective in reducing long-term unemployment, it must not be forgotten that there are certain groups who cannot exit unemployment easily and whose health must be affected by the adverse labour situation. For individuals who remain involuntarily unemployed, inactivity may have an effect on their well-being. First, they face financial difficulties; and second, they are confronted with the loss of self-esteem derived from the lack of perspectives in a society in which work is one of the main keystones.

In the literature, there are several suggestions that this situation results in mental health problems, and, with time, in physical health problems (see Schwefel (1986); Murphy and Athanasou (1999); Kasl and Jones (1998)). However, solid empirical evidence is rare. Most of the empirical studies carry out cross-sectional analysis. This structure does not allow us to distinguish whether the correlation between unemployment and ill health is caused by the negative effect of unemployment on health or whether individuals with poor health are more likely to become unemployed. In order to overcome the endogeneity problem, panel data structure is more adequate than cross-sectional structure. Recently, given the increasing availability from longitudinal data, there has been a considerable increase in studies analyzing the relationship between unemployment and health using panel data. These studies analyse the impact of unemployment on different elements of wellbeing. Winkelmann and Winkelmann (1995) and Gerlach and Stephan (1996) investigate the effect of unemployment on life satisfaction and happiness. Other studies analyze the effect of unemployment on self-esteem and mental health (Goldsmith et al. (1996); Clark et al. (2001)), and also the effects of unemployment on physical health have been analyzed (Gallo et al. (2000)). Most the studies 
reviewed show evidence that unemployment has negative effects on happiness and on mental and physical health.

In the present study, we use longitudinal data (GSOEP) in order to analyse how health satisfaction changes after job loss, and how health satisfaction changes as the period of unemployment increases. Furthermore, we analyse whether unemployed people who find a job feel an improvement in their health satisfaction. At the same time, we also investigate what are the stressors and moderators of the effect of unemployment on health.

The paper is structured as follows. In section 2 a theoretical framework is presented which helps us to better understand the endogenous relationship between labor status and health. Next, in section 3, the data and the empirical results are presented and in section 4, we summarize our findings.

\section{The model}

In order to illustrate better the nature of the endogenous relationship between labor status and health, we use the model developed by Currie and Madrian (1999).

In this model, individuals derive utility from health, leisure and other commodities. By investing time and other health inputs in order to produce health, individuals reduce the total time being sick, which increases the total available time for leisure and market activities. At the same time, hours of work are necessary in order to increase the available income which allows the acquisition of material health inputs and other commodities from which individuals also derive utility.

The utility function of the individuals is defined by:

$$
U_{t}=U\left(H_{t}, C_{t}, L_{t} ; X_{t}, u_{1}, \varepsilon_{1 t}\right)
$$


where $H$ is the stock of health, $C$ is consumption of other goods and $L$ is leisure. $X$ is a vector of exogenous factors affecting preferences, $u_{1}$ is a vector of permanent factors affecting individual preferences, and $\varepsilon_{1}$ denotes shocks to preferences.

Each individual maximizes his or her utility subject to the following constraints:

$$
H_{t}=H\left(H_{t-1}, G_{t}, V_{t} ; Z_{t}, u_{2}, \varepsilon_{2 t}\right)
$$

This restriction is the health production function where $G$ are material health inputs and $V$ are time health inputs. $Z$ is a vector of exogenous factors affecting productivity, $u_{2}$ is a vector of permanent individual factors affecting productivity and $\varepsilon_{2 t}$ denotes a productivity shock.

The budget constraint is:

$$
C_{t}+P_{t} G_{t}+\left(A_{t+1}-A_{t}\right)=Y_{t}
$$

where $A$ denotes assets, $P_{t}$ is the price vector associated to material health inputs, and $Y$ is total income. The different income sources are unearned income $(I)$, labor income $(w W)$ and interest derived from assets $(r A)$ :

$$
Y_{t}=I_{t}+w_{t} W_{t}+r A_{t}
$$

The time constraint is:

$$
L_{t}+V_{t}+W_{t}+S_{t}=1
$$

$S$ is sick time which depends on health stock:

$$
S_{t}=S\left(H_{t}, u_{3}, \varepsilon_{3 t}\right)
$$

where $u_{3}$ is a vector of individual factors determining illness, and $\varepsilon_{3 t}$ are shocks that cause illness.

According to this theoretical framework, there are different possible effects of health on labor supply (Benjamin et al., 2003): health status determines the time an 
individual spends sick and therefore, determines the total time available for market $(W, V)$ (and non-market $(L))$ activities. Poor health may also affect the marginal rate of substitution between leisure and health increasing the 'marginal disutility for work', reducing the labor supply in this way. A negative health shock may also have a negative effect on productivity, which may be translated into lower wages. A reduction in wages has income and substitution effects on labor supply, so that the net effect is not clear. Ill-health may increase the necessity of increasing material health inputs $(G)$, which could increase labor supply due to an adverse income effect. Furthermore, ill-health may have an effect on non-labor income (I), depending on how non-labor income is obtained.

At the same time, according to this framework, labor supply may also affect health in different ways. First, labor supply determines labor income, which at the same time determines the income available to purchase material health inputs. Furthermore, labor supply also determines the time available to produce time health inputs. Labor supply could also be considered as a direct input in the health production function, especially when considering jobs which are physically demanding and when analyzing the effects of labor supply on mental health.

From this model, it can be concluded that health demand will be affected by work and that labor supply will be affected by health. This aspect of the relationship between both variables has to be taken into account in the empirical analysis. We intend to overcome the problem of endogeneity by using the dynamic structure of longitudinal data. 


\section{$-7-$}

\section{Empirical Analysis}

\subsection{Data}

The data used for the empirical analysis is from the German Socio-Economic Panel (GSOEP). The GSOEP is a representative longitudinal survey of the German population (Wagner et al., 1993; Schupp and Wagner, 1995; Schupp and Wagner, 2002). Since participants are interviewed yearly, we are able to follow individuals and their development. With this longitudinal structure, it is possible to analyse changes in health variables over time, and whether these changes are related to changes in other socio-demographic factors.

For our analysis, only individuals with ages between 21 and 65 years old are considered. We consider that this period is the age at which most individuals are active in the labour market. Furthermore, we have selected individuals belonging to households with a specific structure. Concretely, we select households composed by couples $^{4}$ with or without children, excluding single parent households, one person households and households composed by multiple generations. The reason for this selection is that in the analysis of the relationship between unemployment and health satisfaction, we want to see whether or not the effect of unemployment is moderated or stressed by the labour status of the partner.

We select individuals belonging to households which have not suffered relevant family changes during the period considered ${ }^{5}$. In this way we avoid capturing the effect of relevant family changes on changes in health satisfaction.

\footnotetext{
${ }^{4}$ Married or not married.

${ }^{5}$ In GSOEP the relevant family changes considered are: wedding/marriage, moving in with partner or spouse, divorce, separation from partner or spouse, death of partner or spouse, birth of a child, child moves out and other family changes.
} 
We include observations of the first 18 waves of the GSOEP, from 1984 until the year 2001. After carrying out the selections specified above, our sample contains 126,650 observations corresponding to 24,600 individuals.

\subsection{Health Satisfaction and Labor Force Status}

In the empirical analysis health satisfaction is used as a dependent variable. Subjective indicators of health are global indicators which include psychological and social aspects. For this reason, they are closer than objective health indicators to the WHO definition of health: a complete state of physical, mental and social wellbeing. Furthermore, numerous studies have acknowledged their validity and the advantages of using such indicators (e.g., Miilumpalo et al., 1997; Manderbacka et al., 1998; Mossey and Shapiro, 1982; Idler and Benyamini,1997; Helmer et al., 1999; Schwarze et al., 2000; Ahn, 2002 and Sen, 2002). Another interesting characteristic of this variable is the small number of missing values. In our sample of 126,650 observations, we observe only 287 missing values for this variable.

In the questionnaire, individuals answer the question: 'How satisfied are you with your state of health?' and they rate their answer on a scale from 0 to 10,0 being completely unsatisfied and 10 the highest level of satisfaction. The responses are not centred at the value 5 of the scale. The weighted mean for this variable is 6.7 , indicating that individuals tend to report higher levels of health satisfaction.

Labour status has been categorised for the present analysis in three groups: NonWorking (out of the labour force), Unemployed (registered unemployed) and Working (gainfully employed/self-employed) ${ }^{6}$.

\footnotetext{
${ }^{6}$ The labour status variable has undergone some changes since the beginning of the GSOEP. The categories Non-working, Unemployed and Working have been maintained but other new categories have been included. In 1984, apart from the three main categories, the following were also included: non-working: age 65 and older, non-working: in education/training, non-working: military-civil service. These were included in the non-working category in the present study. Later, new categories
} 
Table 1 shows levels of health satisfaction for the different labour status categories considered. For the general sample, the percentage of health satisfaction reports higher than 6 is higher for the employed individuals than for individuals who are out of the labour market. At the same time, individuals out of the labour force more often report higher levels of health satisfaction than unemployed persons. The percentage of low reports of health satisfaction ( 0 and 1$)$ is lower for the employed individuals than for individuals who are unemployed or out of the labour market.

We can conclude that employed individuals are more satisfied with their health than unemployed individuals and individuals out of the labour force. And by comparing unemployed individuals with individuals out of the labour force, we observe that the latter are better off in terms of health satisfaction. If we split the sample into male and female sub-samples, we arrive at the same conclusion. For both, men and women, the employed individuals are most satisfied with their health.

However, this correlation may be derived from two directions of causality. Employed persons are more satisfied with their health, but we don't know if this is because unemployment causes an impoverishment in health or if it is bad health that determines the labour status of the individuals ${ }^{7}$. In order to isolate the direction of causality in which we are interested, we change the object of study, or in other words, we change our dependent variable. From now on, we shall analyse changes in health satisfaction instead of health satisfaction levels. In the following tables, we analyze the effect of different transitions in the labour market on changes in health satisfaction. Due to the availability of longitudinal data, we can identify the

were introduced, such as non-working: maternity leave, non-working: but sometimes secondary job, non-working: but regular secondary job. These have been also included in the non-working category. Finally, in the most recent waves (in 1999 and 2000) information was introduced about the last week before the interview: non-working: but working in the past 7 days, working: but not working in the past seven days. These last categories have been also included in the non-working category, since there is no regular activity in the labour market.

${ }^{7}$ For empirical evidence of the effect of health on labour status see Wang (1997) and Wilson (2001). 
sequence in which the labour market events occur. We can compare health satisfaction of the individuals before and after they have lost their job. In this way, we can observe how health satisfaction is affected by a labour market event.

In table 2, we analyse the relationship between different transitions in the labour market and changes in health satisfaction between $t-1$ and $t^{8}$. If we consider the entire sample, we do not find any major differences in terms of health satisfaction changes between the transitions considered. Comparing individuals who found a job in this period with individuals who were working and remained employed, we observe that the percentage of people reporting positive changes in health satisfaction is higher for the reemployed individuals. However, this group has also a higher percentage of individuals reporting negative health satisfaction. Surprisingly, individuals who lost their job in this period more often report a positive change in health satisfaction than individuals who had been employed and remain employed.

To summarize, by observing changes in health satisfaction between $\mathrm{t}-1$ and $\mathrm{t}$ for individuals who underwent the transitions in the labour market considered, we cannot conclude that there is evidence that job loss has a negative effect on health satisfaction. After splitting the sample into male and female sub-samples, we obtain similar results.

However, until now we have not analysed how health satisfaction responses change if the length of unemployment increases. We have only considered the effect on health satisfaction of losing one's job between $\mathrm{t}-1$ and $\mathrm{t}$. Therefore individuals are

\footnotetext{
${ }^{8}$ In this descriptive analysis, there is a certain bias since individuals with extreme responses $(0$ and 10 ) are included and they can only experience changes in one direction.

In our sample, individuals reporting 0 satisfaction with health represent $1.24 \%$ of all observations. Of all the individuals who answered $0,31 \%$ reported no changes in the following year, and the rest reported positive changes. Individuals reporting health satisfaction of 10 represent $9.23 \%$ of the sample. Of these individuals, $41.5 \%$ reported no change in the following year, and the rest reported negative changes.
} 
not unemployed for longer than one period ${ }^{9}$. But what is the effect on health satisfaction if the individual remains unemployed for more than one year, or more than two years?

In table 3, we analyse health satisfaction changes before and during the unemployment experience, taking different lengths of the period of unemployment into account. At $\mathrm{t}$, some individuals have been unemployed for less than one year, others for between one and two years, and others for between two and three years. We compare health satisfaction at $\mathrm{t}$ with health satisfaction before they lost their job. The reference group in this table are individuals who were working at $\mathrm{t}-1$ and remain employed at $\mathrm{t}^{10}$.

If we consider the entire sample, we observe that individuals who have been unemployed for less than one year have a higher percentage of positive changes in health satisfaction than, and a similar percentage of negative changes in health satisfaction to, individuals who were working at $\mathrm{t}-1$ and remain employed. However, there is a reduction in the percentage of positive changes in health satisfaction and an increase in the percentage of negative changes in health satisfaction if the individual is unemployed for more than one year (and less than 2). Finally, if the individual has been unemployed for more than two years (and less than three) the percentage of positive changes increases again, and the percentage of negative changes decreases.

\footnotetext{
${ }^{9}$ One year approximately.

${ }^{10}$ In this table we compare changes in health satisfaction between $\mathrm{t}-1$ and $\mathrm{t}$ (for individuals who remain employed and for individuals who are less than one year unemployed) with changes in health satisfaction between $\mathrm{t}-2$ and $\mathrm{t}$ (for individuals who are more than one year unemployed and less than 2 years) and with changes in health satisfaction between $t-3$ and $t$ (for individuals who are more than 2 years unemployed). These 3 different variables may not be perfectly comparable, however this comparison is useful for our descriptive purposes.

In the multivariate analysis it will be considered the same period for all individuals included in the analysis.
} 
From this descriptive analysis we conclude that if individuals lose their job, there is actually a positive effect on health satisfaction, which is reduced when individuals are unemployed for more than one year. If they are unemployed for more than two years, they adapt to their situation to a certain extent, since the percentage of positive changes increases and the percentage of negative changes decreases.

If we split the sample into male and female sub-samples, we obtain similar results. Men and women who are unemployed for less than one year more often report positive changes in health satisfaction than individuals who are employed (and who were employed in the previous year). Men also report a negative change in health satisfaction less often. However, women have a higher percentage of negative changes in health satisfaction (than women who are employed) if they have lost their job in the last year.

An interesting result is that while men show evidence of adaptation to some extent, women do not. As in the general sample, after two years of unemployment, men report a higher percentage of positive changes in health satisfaction than men who have been unemployed for between one and two years ${ }^{11}$. However, for women this percentage does not change between women who have been unemployed for more than one but less than two years and women who have been unemployed for more than two years (and less than three) (although the percentage of women reporting negative changes decreases). These results are compatible with the predictions made by the stages model (Eisenberg and Lazarsfeld, 1993). This model explains that after losing their job, the individual goes through different phases, changing from optimism to pessimism and finally even to fatalism.

\footnotetext{
${ }^{11}$ However, the percentage of negative changes in health satisfaction remains unchanged. As a result there is a reduction in the percentage of men reporting no changes in health satisfaction.
} 


\subsection{Multivariate Analysis}

In the present section, we use two models in order to identify the effects of shortand long-term unemployment and a third one in order to identify the effects of reemployment.

In the first model (model A) we consider the period between $\mathrm{t}-1$ and $\mathrm{t}$. At $\mathrm{t}-1$ all individuals are employed. Of these individuals, some remain employed, and others lose their job and remain unemployed until $\mathrm{t}^{12}$. The dependent variable is the change in health satisfaction between $\mathrm{t}-1$ and $\mathrm{t}$. We analyse whether or not job loss between $\mathrm{t}-1$ and $\mathrm{t}$ has an effect on health satisfaction changes those remaining in employment taking as a reference category. This model is illustrated graphically in figure 1 . At $\mathrm{S}$ (a point of time between $\mathrm{t}-1$ and $\mathrm{t}$ ) some of the individuals of the sample suffer a job $\operatorname{loss}^{13}$. This may have an effect on health satisfaction. We compare how the health satisfaction of these individuals has changed between $\mathrm{t}-1$ and $t$ in relation to individuals who remain employed for the whole period. In this model we only consider periods of unemployment shorter than one year since we are only considering the period between $\mathrm{t}-1$ and $\mathrm{t}$. In the following model, we shall consider a longer period in order to identify the effects of short- and long-term unemployment.

In model $\mathrm{B}$, we consider the period between $\mathrm{t}-3$ and $\mathrm{t}$. Again, all individuals are employed at t-3. Some of them remain employed for the entire period, some of them lose their job between $\mathrm{t}-3$ and $\mathrm{t}-2$, others between $\mathrm{t}-2$ and $\mathrm{t}-1$, and others between $\mathrm{t}-1$ and $\mathrm{t}$ (see figure 2).

\footnotetext{
${ }^{12} \mathrm{We}$ do not consider other kind of transitions in the models. Other transitions, like leaving the labour market, are considered as missing values.

If an individual loses his job between $\mathrm{t}-1$ and $\mathrm{t}$ but finds a job again before $\mathrm{t}$, it is also considered as a missing value.

${ }^{13} \mathrm{~S}$ is not constant across individuals. For some, $\mathrm{S}$ will be closer to $\mathrm{t}-1$ and for others, closer to $\mathrm{t}$.
} 
The dependent variable is change in health satisfaction between t-3 and t. The objective of this model is to analyse whether or not there is a different effect on health satisfaction depending on whether the individual loses his or her job at the beginning of the period or at the end of the period. If the individual loses the job at the beginning of the period (between $\mathrm{t}-3$ and $\mathrm{t}-2$ ) and remains unemployed, at $\mathrm{t}$, he or she will have been unemployed for more than two years. However, if the individual loses his or her job at the end of the period (between $t-1$ and $t$ ), at the or she will have been unemployed for less than one year. If individuals suffer a job loss at S1 (between t-3 and t-2), at t, they will have been unemployed for most of the period considered ( 3 years). If the job loss occurs at S2, the individual will have been unemployed for more than one year (and less than two years) at t. Finally, if the individual loses his or her job in $\mathrm{S} 3$, at $\mathrm{t}$, the duration of the period of unemployment is less than one year. We compare the changes in health satisfaction between $\mathrm{t}-3$ and $\mathrm{t}$ of individuals who suffered job loss at S1, S2 and S3 with the health satisfaction changes of individuals who remained employed for the whole period.

In the third model (model $\mathrm{C}$ ), as in model A, we consider the period between $\mathrm{t}-1$ and t. However, in this model, we do not select individuals who are employed at t-1, but individuals who are unemployed at $\mathrm{t}-1$, in order to analyse the effect of finding a job on health satisfaction. Some of these individuals remain unemployed until $t$, and some of them find a job between $\mathrm{t}-1$ and $\mathrm{t}$. We analyse the effect on health satisfaction of finding a job, taking as a reference group the individuals who remain unemployed. This model is illustrated in figure 3. At S (a point of time between $\mathrm{t}-1$ and t) some of the individuals who were unemployed at $t-1$ find a job. We compare 
the health satisfaction changes of these individuals with the health satisfaction changes of individuals who remain unemployed.

For each of the three models (A, B and C) 2 sub-models have been estimated. In the first one, no interaction effects are considered. In the second sub-model, we analyse the effect of job loss/reemployment using interaction effects. Furthermore, every sub-model is calculated separately for men and women, since, in the descriptive analysis, we identified some differences between men and women regarding the relationship between labour status and health satisfaction.

In the three models (and the corresponding sub-models) we have included health satisfaction at the beginning of the period as an explanatory variable (Warr and Jackson, 1987). The idea behind this is that individuals with low levels of health satisfaction are more likely to report positive changes in health satisfaction than individuals with high levels of health satisfaction. Similarly, individuals with high levels of health satisfaction are more likely to report negative changes in health satisfaction than individuals with low levels of health satisfaction. We also introduce into the models a dummy variable that takes the value 1 if the individual is in the panel 4 waves or more and 0 if the individual is less than 4 waves in the panel. This is because there is a certain development of the responses when a individual remains in the panel for several waves (Schräpler, 1997; Schräpler, 2001). In tables 4 to 6 , all explanatory variables (and dependent variables) for the three models and the corresponding sub-models are described.

Given the large number of categories of the dependent variable (health satisfaction changes $)^{14}$, we treat the dependent variable as a continuous one, and apply the common panel data methodology for continuous variables.

\footnotetext{
${ }^{14}$ Since health satisfaction is an ordinal variable with 11 categories (from 0 to 10 ), health satisfaction differences can take 21 different values.
} 
In order to decide whether to use random or fixed effect estimators we carry out the corresponding Hausman test for our models, obtaining the result that GLS is the most efficient estimator.

In tables 7-12, the results of the random effects estimations for the models A, B and $\mathrm{C}$ and the corresponding sub-models are presented.

\section{$\underline{\text { Model A }}$}

For men (table 7, model A.1.), job loss has a significant and negative effect on health satisfaction changes between $\mathrm{t}-1$ and $\mathrm{t}$, as we already saw in the descriptive analysis. In sub-model A.2, we control for the effect of job loss by introducing different interaction terms. Of the interaction effects introduced, the only ones to have a significant effect on changes in health satisfaction are job loss for individuals who are older than 50 and for individuals who were main earners ${ }^{15}$ at $\mathrm{t}-1$. From this result, we can conclude that age is a stressor of job loss. Or in other words, individuals who are older than 50 suffer more from a job loss than younger people. Surprisingly, job loss for main earners has a positive effect on health satisfaction changes. For men, the fact that the partner is unemployed or out of the labour force moderates the effect of losing their own job, although we expected the opposite result. One possible explanation for this result is the thesis put forward by Clark (2001) in the analysis of unemployment as a social norm. Clark maintains that the psychological impact of one's own unemployment may be reduced by a higher level of unemployment among relevant others.

In table 8 , the results of the estimation of the model A for the female sub-sample are presented. According to the results of the sub-model A.1, we do not observe a significant effect of job loss on health satisfaction changes. In the sub-model A.2,

\footnotetext{
${ }^{15}$ At $\mathrm{t}-1$ all individuals were employed. Main earners were those individuals whose partners were unemployed or out of the labour force at $\mathrm{t}-1$.
} 
where the effect of job loss is controlled by interaction terms, only the interaction term job loss and age are significant and negative. Again, age acts as a stressor of job loss.

As we pointed out in previous sections, in model A we are only analysing shortterm unemployment, since only the period between $\mathrm{t}-1$ and $\mathrm{t}$ is considered. Therefore, we can conclude that short-term unemployment has significant effects for men but not for women. From the interaction effects analysis, we conclude that age is an stressor of the effect of job loss for both men and women. Furthermore, if the partner is unemployed or out of the labour force at $t-1$, the effect of job loss for men is reduced. One plausible explanation for this result is that the effect of unemployment is reduced by the unemployment suffered by relevant others.

\section{$\underline{\text { Model B }}$}

In model $\mathrm{B}$, the period between $\mathrm{t}-3$ and $\mathrm{t}$ is considered. At $\mathrm{t}-3$, all individuals are employed. From these individuals, some remain employed until $t$, some lose their job between $\mathrm{t}-3$ and $\mathrm{t}-2$ and remain unemployed until t, others lose their job between $\mathrm{t}-2$ and $\mathrm{t}-1$ and remain unemployed until $\mathrm{t}$, and others lose their job between $\mathrm{t}-1$ and $\mathrm{t}$. Individuals who lose their job between $\mathrm{t}-1$ and $\mathrm{t}$ remain in unemployment for a maximum of one year, as in model A. And individuals who lose their job before $\mathrm{t}-1$ and remain unemployed until $\mathrm{t}$ are unemployed for more than one year (and more than two years if the individual loses his or her job between $\mathrm{t}-2$ and $\mathrm{t}-3$ ). We compare how these different labour market events affect changes in health satisfaction (between $\mathrm{t}-3$ and $\mathrm{t}$ ).

In table 9, the results of the analysis for the male sub-sample are presented. For men (sub-model B.1), job loss between $\mathrm{t}-1$ and $\mathrm{t}$ is significant (and negative). Job loss between $\mathrm{t}-2$ and $\mathrm{t}-3$ also has a significant and negative effect on health satisfaction 
changes. Finally, job loss between t-1 and t-2 does not have a significant effect on health satisfaction changes. Summarizing, for men, as we already observed in model A, short-term unemployment has an effect on health satisfaction changes. Furthermore, losing their job and remaining unemployed for more than two years also has a negative effect on health satisfaction changes. The coefficient of job loss between $\mathrm{t}-1$ and $\mathrm{t}$ is bigger (more negative) than the one corresponding to job loss between $\mathrm{t}-2$ and $\mathrm{t}-3$.

In sub-model B.2, different interaction terms have been considered. In this case we interact job loss between $\mathrm{t}-1$ and $\mathrm{t}$ with other covariates. The reason for using job loss between $\mathrm{t}-1$ and $\mathrm{t}$ is that, of the different labour market events considered, this is the one that has the greatest effect on changes in health satisfaction. Job loss for people older than 50 has a significant and negative effect on health satisfaction changes. Again, we conclude that age acts as stressor in a negative event in the labour market. Job loss for individuals with children under 16 also has a significant and negative effect on health satisfaction changes.

In table 10 , the results of the estimation of the model B for women are presented. Regarding the job loss variables (in model B.1), only job loss between t-2 and t-3 has a significant effect on health satisfaction changes, and the corresponding coefficient is negative. For women, losing their job before $\mathrm{t}-1$ and remaining unemployed until $\mathrm{t}$ has no significant effect on health satisfaction changes, taking the individuals who remain employed for the whole period (before $t-3$ and $t$ ) as a reference. In sub-model B.2 we introduce different interaction effects between job loss between $\mathrm{t}-2$ and $\mathrm{t}-3$ and various covariates. We interact job loss between $\mathrm{t}-2$ and $\mathrm{t}-3$ because of the labour market events considered, this is the one which has an 
effect on health satisfaction changes. Of the different interaction terms introduced, none has a significant effect on health satisfaction changes.

To summarize, while for men short-term unemployment has a significant and negative effect on health satisfaction changes, for women it does not. One plausible explanation for this result is that usually, employed women, apart from doing their job outside the home, are responsible for the housework. That is, most women work both at home and outside the home. Therefore, the first reaction after job loss may be one of relief. Long-term unemployment (more than two years) has a significant effect for both, men and women.

\section{$\underline{\text { Model C }}$}

Finally, in tables 11 and 12, we present the results of the calculation using model C. With this model, we are analysing the effect of reemployment on health satisfaction. The main difference to the other models is the sample selection. While in models A and $\mathrm{B}$, all individuals in the sample were employed at the beginning of the period, in model $\mathrm{C}$, all individuals are unemployed at $\mathrm{t}-1$. Some of them remain unemployed until $\mathrm{t}$ and others find a job between $\mathrm{t}-1$ and $\mathrm{t}$ and remain employed until t. We test whether there is a different effect on health satisfaction changes between these two different labour market events.

In table 11 , the results of the model $\mathrm{C}$ estimation for the male sub-sample are presented. In model C.1., we observe that reemployment has a significant and positive effect on health satisfaction changes. In model C.2, interaction effects have been introduced. We interact reemployment with age, having children, being from eastern Germany, and being unemployed for more than 2 years. None of these interaction effects have a significant effect on health satisfaction changes. 
In table 12 we present the results of the calculations using model $\mathrm{C}$ for the female sub-sample. In sub-model C.1 we observe that reemployment has a significant and positive effect for women. In sub-model C.2, only one of the interaction effects introduced is significant. Reemployment for women who have children under 16 in the household is significant and a positive. This may be due to the higher income needs existing in a household with children under 16.

To summarize, for unemployed men and women, reemployment has a positive effect on health satisfaction, independently of age and independently of the length of time for which the individual was unemployed.

\section{Summary and Conclusions}

Unemployment, and especially long-term unemployment, has become one of the main concerns of the German government.

One of the measures proposed by the German government in order to motivate job search is to reduce the maximal duration of the period to which individuals have the right to receive unemployment benefits. The background to this proposal is the belief that there is a voluntary component in unemployment. In other words, there is the belief that some unemployed people remain unemployed longer because they do not feel under pressure to find another job due to the generous financial support of the state. However, not all unemployed persons remain in unemployment voluntarily. For many individuals (especially for older ones), unemployment is a situation from which it is difficult to emerge, and for these individuals, the chances of reemployment decrease as the period of unemployment increases. Some individuals may suffer serious consequences from this unfavourable situation. Unemployment may cause health problems to those persons who can not accommodate to their situation. Typically, there is a loss of self-esteem due to the 
impossibility of changing a situation with which the individual (and his/her family) is not satisfied.

In the present study we have analysed the health situation of unemployed people. The main objective has been to analyse how health changes after job loss and how health develops as the length of the period of unemployment increases. The theoretical model presented predicted that there is an impact of the labor status on health. However, the endogenous relationship between labor status and health may lead to biased estimations of the effect of unemployment on health. Therefore; we used the longitudinal structure of the GSOEP in order to overcome this endogeneity problem. We used three different models, two models (A and B) in order to investigate the effect of short- and long-term unemployment on health satisfaction, and a third one (model C) in order to analyse the effect of reemployment on health satisfaction. We calculated these three models separately for men and women, because, in the descriptive analysis, we had already identified some differences between men and women in the effect of unemployment on health satisfaction.

The main conclusion from the empirical analysis is that while, for men, short-term unemployment has a negative effect on health satisfaction changes, for women, short-term unemployment does not have a significant effect on health satisfaction changes. For both sub-samples (men and women), being unemployed for more than two years has a significant and negative effect on health satisfaction changes. Reemployment has, for both men and women, a significant and positive effect on health satisfaction changes, independently of the duration of the period of unemployment. 


\section{References}

1. Ahn, N. (2002) Assessing self-assessed health data. FEDEA Working Paper 2002-24.

2. Benjamin, D., Brandt, L. and Fan, J-Z. (2003) Ceaseless Toil? Health and labor supply of the elderly in rural China. Working Paper of the Economics Department, University of Toronto.

3. Clark, A.E. (2001) Unemployment as a social norm: psychological evidence from panel data. DELTA Working Paper October.

4. Clark, A.E., Georgellis, Y. and Sanfey, P. (2001) Scarring: the psychological impact of past unemployment, Economica, 68, 221-241.

5. Currie, J. and Madrian, B.C. (1999) Health, health insurance and the labour market, in Handbook of Labor Economics, vol.3. (Eds.) O.Ashenfelter and D. Card, North-Holland.

6. Eisenberg, P. and Lazarsfeld, P.F. (1938). The psychological effects of unemployment, Psychological Bulletin, 35, 358-390.

7. Gallo, W.T., Bradley, E.H., Siegel, M. and Kasl, S.V. (2000) Health effects of involuntary job loss among older workers: findings from the health and retirement survey. Journal of Gerontology: SOCIAL SCIENCES, 55B(3), S131S140.

8. Gerlach, K. and Stephan, G. (1996) A paper on unhappiness and unemployment in Germany. Economic Letters, 52, 325-330.

9. Gerlach, K. and Stephan, G. (2001) Lebenszufriedenheit und Erwerbstatus: Ostund West-deutschland in Vergleich. Mitteilungen aus der Arbeitsmarktund Berufsforschung, 4, 515-529. 
10. Goldsmith, A.H., Veum, J.R. and Darity, W. (1996) The impact of labor force history on self-esteem and its component parts, anxiety, alienation and depression. Journal of Economic Psychology, 17, 183-220.

11. Helmer, C., Barberger-Gateau, P., Letenneur, L. and Dartigues, J-F. (1999) Subjective health and mortality in French elderly women and men. Journal of Gerontology: SOCIAL SCIENCES, 54B(2), 84-92.

12. Idler, E.L. and Benyamini, Y. (1997) Self-rated health and mortality: A review of twenty-seven community studies. Journal of Health and Social Behaviour, 38(March), 21-37.

13. Kasl, S. and Jones, B.A. (1998) The impact of job loss and retirement on health, in Social Epidemiology (Eds) L.F. Berkman and I. Kawachi, Oxford University Press, Oxford.

14. Leber, U. (2001) Ältere - ein Schatz muss gehoben werden. IAB Materialen. Informationdienst des Instituts für Arbeitsmarkt- und Berufsforschung der Bundesanstalt für Arbeit. Ausgabe Nr. 2.

15. Manderbacka, K., Lahelma, E. and Martikainen, P. (1998) Examining the continuity of self-rated health. International Journal of Epidemiology, 27, 208213.

16. Miilumpalo, S., Vuori, I., Oja, P., Pasanen and Urponen, H. (1997) Self-rated health status as a health measure: The predictive value of self-reported health status on the use of physician services and on mortality in the working age population. Journal of Clinical Epidemiology, 50(5), 517-528.

17. Mossey, J.M. and Shapiro, E. (1982) Self-rated health: a predictor of mortality among the elderly. American Journal of Public Health, 72(8), 800-807. 
18. Murphy, G.C. and Athanasou (1999) The effect of unemployment on mental health. Journal of Occupational and Organizational Psychology, 72, 83-99.

19. Schräpler, J-P. (1997) Eine empirische Erklärung von formalen Antwortstilen Stereotypes Antwortverhalten und Zustimmungstendenzen im Sozioökonomischen Panel (SOEP). Kölner Zeitschrift für Soziologie und Sozialpsychologie, 49(4), 728-746.

20. Schräpler, J-P. (2001) Respondent behavior in panel studies: a case study of the German Socio-Economic Panel (GSOEP). DIW Discussion Paper 244.

21. Schupp, J. and Wagner, G. (1995) The German Socio-Economic Panel: a database for longitudinal international comparisons. Innovation, 8(1), 95-108.

22. Schupp, J. and Wagner, G. (2002) Maintenance of and innovation in long-term panel studies: the case of the German Socio-Economic Panel (GSOEP). Allgemeines Statistisches Archiv, 86, 163-175.

23. Schwarze, J., Andersen, H.H. and Anger, S. (2000) Self-rated health and changes in self-rated health as predictors of mortality. First evidence from German Panel data. DIW Discussion Paper 203.

24. Schwefel, D. (1986) Unemployment, health and health services in Germanspeaking countries. Social Science and Medicine, 22(4), 409-430.

25. Sen, A. (2002) Health: perception versus observation. British Medical Journal, 324(April), 860-861.

26. Wagner, G., Burkhauser, R.V. and Behringer, F. (1993) The English language public use file of the German Socio-Economic Panel. The Journal of Human Resources, 28(2), 429-433.

27. Wang, W. (1997) Semi-parametric estimation of the effect of health on labour force participation of married women, Applied Economics, 29(3), 325-329. 
28. Warr, P. and Jackson, P. (1987) Adapting to the unemployed role: a longitudinal investigation. Social Science and Medicine, 25(11), 1219-1224.

29. Wilson, S.E. (2001) Work and the accommodation of chronic illness: A reexamination of the health-labour supply relationship, Applied Economics, 33(9), $1139-1156$.

30. Winkelmann, L. and Winkelmann, R. (1995) Unemployment: where does it hurt?. Centre for Economic Policy Research Discussion Paper 1093. 
Figure 1. Model A: Effect of short-term unemployment on health satisfaction.

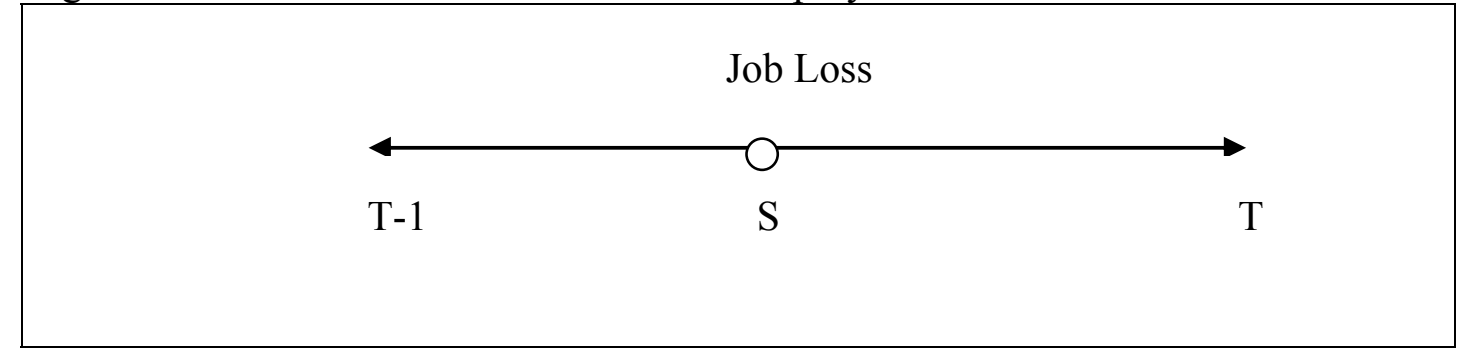

Figure 2. Model B: Effect of short- and long-term unemployment on health satisfaction.

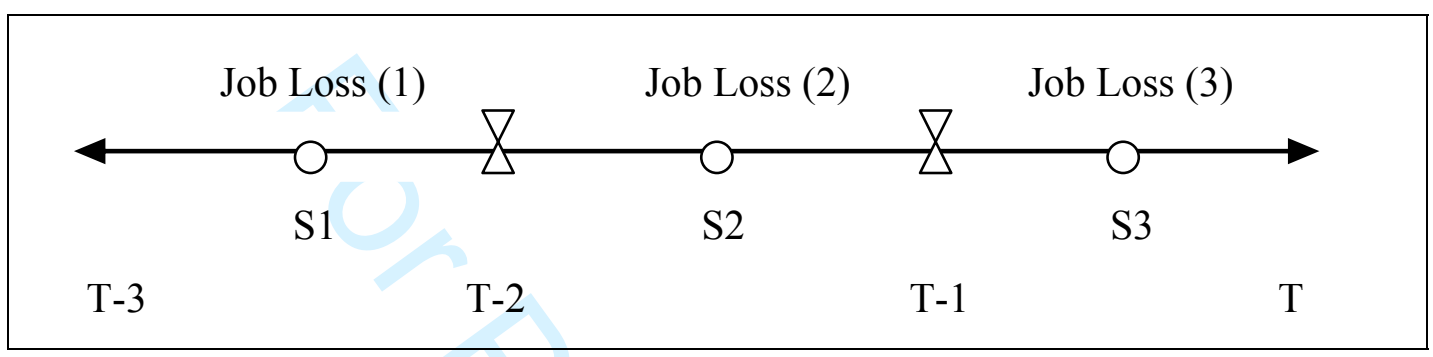

Figure 3. Model C: Effect of reemployment on health satisfaction.

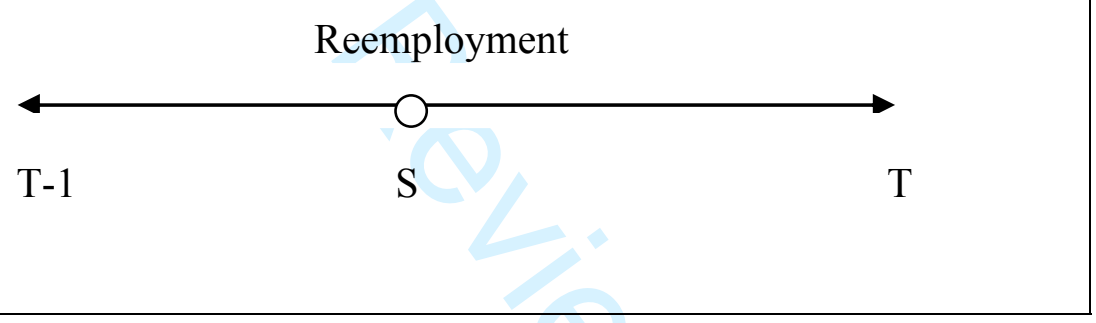


Table 1. Relationship between health satisfaction and labour status

\begin{tabular}{cccc}
\hline Health Satisfaction & Working & Unemployed & Non-Working \\
\hline Entire sample & $(N=87,017)$ & $(N=7,870)$ & $(N=31,476)$ \\
$(0,1)$ & 1.26 & 4.04 & 4.22 \\
$(2, . ., 6)$ & 33.85 & 47.92 & 43.93 \\
$(7, . ., 10)$ & 64.89 & 48.04 & 51.85 \\
& $(100 \%)$ & $(100 \%)$ & $(100 \%)$ \\
Men & & & \\
$(0,1)$ & $(N=51,023)$ & $(N=4,004)$ & $(N=8,921)$ \\
$(2, . ., 6)$ & 1.19 & 4.85 & 6.08 \\
$(7, . ., 10)$ & 32.99 & 46.08 & 46.32 \\
& 65.82 & 49.07 & 47.60 \\
Women & $(100 \%)$ & $(100 \%)$ & $(100 \%)$ \\
$(0,1)$ & & \\
$(2, . ., 6)$ & $(N=35,994)$ & $(N=3,866)$ & $(N=22,555)$ \\
$(7, . ., 10)$ & 1.36 & 3.10 & 3.46 \\
& 35.08 & 50.06 & 42.96 \\
& 63.56 & 46.84 & 53.58 \\
Pooled data, years 1984-2001 & $(100 \%)$ & $(100 \%)$ & $(100 \%)$ \\
Weighted frequencies. Non-weighted number of observations. & & Source: GSOEP
\end{tabular}


Table 2. Relationship between different transitions in the labour market and changes in health satisfaction

\begin{tabular}{cccccc}
\hline Change in & $t$-1: Unemp. & $t$-1: Working & $t$-1: Unemp. & $t$-1: Working & Others \\
Health Satisfaction & $t$ : Working & $t$ : Unemp. & T: Unemp. & $t$ : Working & \\
\hline Entire sample & $(N=1,607)$ & $(N=2,145)$ & $(N=2,865)$ & $(N=58,987)$ & $(N=26,091)$ \\
$>0$ & 34.22 & 35.36 & 34.68 & 32.14 & 34.85 \\
$=0$ & 28.07 & 28.62 & 28.58 & 31.64 & 30.04 \\
$<0$ & 37.72 & 36.02 & 36.74 & 36.22 & 35.11 \\
& $(100 \%)$ & $(100 \%)$ & $(100 \%)$ & $(100 \%)$ & $(100 \%)$ \\
Men & $(N=821)$ & $(N=1,172)$ & $(N=1,460)$ & $(N=35,209)$ & $(N=7,692)$ \\
$>0$ & 34.89 & 36.03 & 34.73 & 31.87 & 35.25 \\
$=0$ & 27.19 & 29.14 & 29.51 & 31.83 & 30.27 \\
$<0$ & 37.92 & 34.83 & 35.75 & 36.30 & 34.48 \\
& $(100 \%)$ & $(100 \%)$ & $(100 \%)$ & $(100 \%)$ & $(100 \%)$ \\
Women & $(N=786)$ & $(N=973)$ & $(N=1,405)$ & $(N=23,778)$ & $(N=18,399)$ \\
$>0$ & 33.46 & 34.48 & 34.61 & 32.55 & 34.68 \\
$=0$ & 29.05 & 27.94 & 27.39 & 31.36 & 29.94 \\
$<0$ & 37.48 & 37.58 & 38.00 & 36.09 & 35.38 \\
& $(100 \%)$ & $(100 \%)$ & $(100 \%)$ & $(100 \%)$ & $(100 \%)$ \\
\hline Pooled data, years 1984-2001 & & & & Source: GSOEP \\
Weighted frequencies. Non-weighted number of observations. & & &
\end{tabular}


Table 3. Relationship between the length of the unemployment period and changes in health satisfaction (between before and during the unemployment experience)

\begin{tabular}{|c|c|c|c|c|}
\hline Change in & T-1: Working & T: Unemployed & T: Unemployed & T: Unemployed \\
\hline Health Satisfaction & T: Working & $\leq 12$ months & $>12$ months and $\leq 4$ & $>24$ months and $\leq 36$ \\
\hline Entire sample & $(N=58,987)$ & $(N=2,083)$ & $(N=484)$ & $(N=206)$ \\
\hline$>0$ & 32.14 & 35.24 & 32.15 & 35.86 \\
\hline$=0$ & 31.64 & 28.55 & 27.65 & 25.53 \\
\hline \multirow[t]{2}{*}{$<0$} & 36.22 & 36.21 & 40.21 & 38.61 \\
\hline & $(100 \%)$ & $(100 \%)$ & $(100 \%)$ & $(100 \%)$ \\
\hline Men & $(N=35,209)$ & $(N=1,128)$ & $(N=243)$ & $(N=99)$ \\
\hline$>0$ & 31.87 & 35.88 & 33.02 & 40.04 \\
\hline$=0$ & 31.83 & 28.82 & 23.80 & 16.65 \\
\hline \multirow[t]{2}{*}{$<0$} & 36.30 & 35.30 & 43.18 & 43.32 \\
\hline & $(100 \%)$ & $(100 \%)$ & $(100 \%)$ & $(100 \%)$ \\
\hline Women & $(N=23,778)$ & $(N=955)$ & $(N=241)$ & $(N=107)$ \\
\hline$>0$ & 32.55 & 34.42 & 31.20 & 31.45 \\
\hline$=0$ & 31.36 & 28.19 & 31.83 & 34.92 \\
\hline \multirow[t]{2}{*}{$<0$} & 36.09 & 37.39 & 36.97 & 33.63 \\
\hline & $(100 \%)$ & $(100 \%)$ & $(100 \%)$ & $(100 \%)$ \\
\hline
\end{tabular}


Table 4. Description of the dependent and explanatory variables of Model A

\begin{tabular}{|c|c|}
\hline Variables & Description \\
\hline Change in Health Satisfaction $(++)$ & Health Satisfaction Changes (between T-1 and T) \\
\hline Health Satisfaction at t-1 & Reported Health Satisfaction at $\mathrm{t}-1$ \\
\hline Change in Household Income & $\begin{array}{l}=0 \text { if there is a positive change or no change in household income. } \\
=1 \text { if there is a negative change in household income between } \mathrm{T}-1 \text { and } \mathrm{T}\end{array}$ \\
\hline Age T-1 & Age at $\mathrm{t}-1$ \\
\hline Not German & $\begin{array}{l}=0 \text { if the individual was born in Germany or immigrated before } 1949 \\
=1 \text { if the individual immigrated after } 1949\end{array}$ \\
\hline East German & $\begin{array}{l}=0 \text { if the individual lives in western Germany } \\
=1 \text { if the individual lives in eastern Germany }\end{array}$ \\
\hline Job Loss & $\begin{array}{l}=0 \text { if the individual remains employed } \\
=1 \text { if the individual loses his job between } \mathrm{T}-1 \text { and } \mathrm{T} \text { and remains } \\
\text { unemployed at least until } \mathrm{T}\end{array}$ \\
\hline Long Participation & $\begin{array}{l}=0 \text { if the individual participates less than } 4 \text { waves (pr } 4 \text { waves) in } \\
\text { the panel } \\
=1 \text { if the individual participates for more than } 4 \text { waves }\end{array}$ \\
\hline Job Loss*Age & $\begin{array}{l}\text { Interaction Variable: Job loss and a dummy variable which takes the } \\
\text { value } 1 \text { if the individual is older than } 50 \text { years old and } 0 \text { otherwise }\end{array}$ \\
\hline Job Loss*Children & $\begin{array}{l}\text { Interaction Variable: Job loss and a dummy variable which takes the } \\
\text { value } 1 \text { if there are children under } 16 \text { in the household and } 0 \text { otherwise }\end{array}$ \\
\hline Job Loss*High Education & $\begin{array}{l}\text { Interaction Variable: Job loss and a dummy variable which takes the } \\
\text { value } 1 \text { if the individual has completed a college education or a } \\
\text { vocational training and } 0 \text { otherwise }\end{array}$ \\
\hline Job Loss*Main Earner & $\begin{array}{l}\text { Interaction Variable: Job loss and a dummy variable which takes the } \\
\text { value } 1 \text { if the partner is unemployed or out of the labour force at } T-1 \text { and } \\
0 \text { if the partner is working at } T-1\end{array}$ \\
\hline
\end{tabular}

$(++)$ Dependent variable. Source: GSOEP Model A.1: No interaction effects. Model A.2: Interaction effects 
Table 5. Description of the dependent and explanatory variables of Model B

\begin{tabular}{|c|c|}
\hline Variables & Description \\
\hline Change in Health Satisfaction $(++)$ & Health Satisfaction Changes (between T-3 and T) \\
\hline Health Satisfaction in T-3 & Reported Health Satisfaction in T-3 \\
\hline Change in Household Income & $\begin{array}{l}=0 \text { if there is a positive change or no change in household income } \\
=1 \text { if there is a negative change in household income between } \mathrm{T}-3 \text { and } \mathrm{T}\end{array}$ \\
\hline Age T-3 & Age in $\mathrm{T}-3$ \\
\hline Not German & $\begin{array}{l}=0 \text { if the individual was born in Germany or immigrated before } 1949 \\
=1 \text { if the individual immigrated after } 1949\end{array}$ \\
\hline East German & $\begin{array}{l}=0 \text { if the individual lives in western Germany } \\
=1 \text { if the individual lives in eastern Germany }\end{array}$ \\
\hline Job Loss S1 & $\begin{array}{l}=0 \text { if the individual remains employed } \\
=1 \text { if the individual loses his job between T-3 and T- } 2 \text { and remains } \\
\text { unemployed at least until } \mathrm{T}\end{array}$ \\
\hline Job Loss S2 & $\begin{array}{l}=0 \text { if the individual remains employed } \\
=1 \text { if the individual loses his job between } \mathrm{T}-2 \text { and } \mathrm{T}-1 \text { and remains } \\
\text { unemployed at least until } \mathrm{T}\end{array}$ \\
\hline Job Loss S3 & $\begin{array}{l}=0 \text { if the individual remains employed } \\
=1 \text { if the individual loses his job between } \mathrm{T}-1 \text { and } \mathrm{T} \text { and remains } \\
\text { unemployed at least until } \mathrm{T}\end{array}$ \\
\hline Long Participation & $\begin{array}{l}=0 \text { if the individual participates for less than } 4 \text { waves (or } 4 \text { waves) in } \\
\text { the panel } \\
=1 \text { if the individual participates for more than } 4 \text { waves }\end{array}$ \\
\hline Job Loss S3*Age & $\begin{array}{l}\text { Interaction Variable: Job loss } \mathrm{S} 3 \text { and a dummy variable which takes the } \\
\text { value } 1 \text { if the individual is older than } 50 \text { years old and } 0 \text { otherwise }\end{array}$ \\
\hline Job Loss S3*Children & $\begin{array}{l}\text { Interaction Variable: Job loss } \mathrm{S} 3 \text { and a dummy variable which takes the } \\
\text { value } 1 \text { if there are children under } 16 \text { in the household and } 0 \text { otherwise }\end{array}$ \\
\hline Job Loss S3*High Education & $\begin{array}{l}\text { Interaction Variable: Job loss } \mathrm{S} 3 \text { and a dummy variable which takes the } \\
\text { value } 1 \text { if the individual has completed a college education or a } \\
\text { vocational training and } 0 \text { otherwise }\end{array}$ \\
\hline Job Loss S3*Main Earner & $\begin{array}{l}\text { Interaction Variable: Job loss } \mathrm{S} 3 \text { and a dummy variable which takes the } \\
\text { value } 1 \text { if the partner is unemployed or out of the labour force at } \mathrm{T}-1 \text { and } \\
0 \text { if the partner is working at } \mathrm{T}-1\end{array}$ \\
\hline
\end{tabular}

$(++)$ Dependent variable. Source: GSOEP

Model B.1: No interaction effects. Model B.2: Interaction effects 
Table 6. Description of the dependent and explanatory variables of Model C

\begin{tabular}{|c|c|}
\hline Variables & Description \\
\hline Change in Health Satisfaction $(++)$ & Health Satisfaction Changes (between T-1 and T) \\
\hline Health Satisfaction at T-1 & Reported Health Satisfaction at $\mathrm{t}-1$ \\
\hline Change in Household Income & $\begin{array}{l}=0 \text { if there is a positive change or no change in household income } \\
=1 \text { if there is a negative change in household income between } \mathrm{T}-1 \text { and } \mathrm{T}\end{array}$ \\
\hline Age T-1 & Age at $\mathrm{T}-1$ \\
\hline Not German & $\begin{array}{l}=0 \text { if the individual was born in Germany or immigrated before } 1949 \\
=1 \text { if the individual immigrated after } 1949\end{array}$ \\
\hline East German & $\begin{array}{l}=0 \text { if the individual lives in Western Germany } \\
=1 \text { if the individual lives in Eastern Germany }\end{array}$ \\
\hline High Educated & $\begin{array}{l}=1 \text { if the individual has completed a college education or a vocational } \\
\text { training } \\
=0 \text { otherwise }\end{array}$ \\
\hline Reemployment & $\begin{array}{l}=0 \text { if the individual remains unemployed } \\
=1 \text { if the individual finds a job between } \mathrm{T}-1 \text { and } \mathrm{T} \text { and remains } \\
\text { employed at least until } \mathrm{T}\end{array}$ \\
\hline Long Participation & $\begin{array}{l}=0 \text { if the individual participates for less than } 4 \text { waves (or } 4 \text { waves) in the } \\
\text { panel } \\
=1 \text { if the individual participates for more than } 4 \text { waves }\end{array}$ \\
\hline Reemployment*Age & $\begin{array}{l}\text { Interaction Variable: Reemployment and a dummy variable which takes } \\
\text { the value } 1 \text { if the individual is older than } 50 \text { years old and } 0 \text { otherwise }\end{array}$ \\
\hline Reemployment*Children & $\begin{array}{l}\text { Interaction Variable: Reemployment and a dummy variable which takes } \\
\text { the value } 1 \text { if there are children under } 16 \text { in the household and } 0 \\
\text { otherwise }\end{array}$ \\
\hline Reemployment*Eastern Germany & $\begin{array}{l}\text { Interaction Variable: Reemployment and a dummy variable which takes } \\
\text { the value } 1 \text { if the individual lives in Eastern Germany and } 0 \text { otherwise }\end{array}$ \\
\hline Reemployment*>24 months unemployed & $\begin{array}{l}\text { Interaction Variable: Job loss and a dummy variable which takes the } \\
\text { value } 1 \text { if the individual has been until T-1 more than } 24 \text { months } \\
\text { unemployed and } 0 \text { otherwise }\end{array}$ \\
\hline
\end{tabular}

Model C.1:No Interaction effects. Model C.2: Interaction effects.
.+ Dependent variable. 
Table 7. Model A: Random effects estimations. Years: 1984-2001. Men.

\begin{tabular}{|c|c|c|c|c|c|c|}
\hline & \multicolumn{3}{|c|}{ MODEL A.1 } & \multicolumn{3}{|c|}{ MODEL A.2 } \\
\hline & \multicolumn{2}{|l|}{ Coeff. } & St.Errors & Coeff. & & St.Errors \\
\hline Cons. & 5.475 & $* * * *$ & $(0.060)$ & 3.887 & $* * * *$ & $(0.045)$ \\
\hline H. Satisf. T-1 & -0.619 & $* * * *$ & $(0.005)$ & -0.558 & $* * * *$ & $(0.006)$ \\
\hline Change HH Inc. $(<0=1)$ & -0.072 & $* * * *$ & $(0.017)$ & -0.094 & $* * * *$ & $(0.021)$ \\
\hline Age T-1 & -0.028 & $* * * *$ & $(0.001)$ & & & \\
\hline Not German=1 & 0.056 & & $(0.029)$ & 0.034 & & $(0.032)$ \\
\hline East German $=1$ & -0.150 & $* * * *$ & $(0.030)$ & -0.169 & $* * * *$ & $(0.034)$ \\
\hline Job Loss $\mathrm{S}(*)$ & -0.156 & $* * *$ & $(0.057)$ & & & \\
\hline Long Participation $(* *)$ & -0.071 & $* * * *$ & $(0.018)$ & -0.134 & $* * * *$ & $(0.020)$ \\
\hline Job Loss*Age $(>50=1)$ & & & & -0.518 & $* * *$ & $(0.152)$ \\
\hline Job Loss $*$ Children & & & & -0.047 & & $(0.148)$ \\
\hline Job Loss*High Education & & & & -0.049 & & $(0.138)$ \\
\hline Job Loss*Main Earner (T-1) & & & & 0.370 & $* *$ & $(0.151)$ \\
\hline & \multicolumn{3}{|c|}{$\mathrm{N}=41.084$} & \multicolumn{3}{|c|}{$\mathrm{N}=26.777$} \\
\hline & \multirow{2}{*}{\multicolumn{3}{|c|}{$\begin{array}{l}\text { Wald chi2 }(7)=18,555.65 * * * * \\
R h o=0.1711\end{array}$}} & \multirow{2}{*}{\multicolumn{3}{|c|}{$\begin{array}{l}\text { Wald chi } 2(9)=10,157.01 * * * * \\
\mathrm{Rho}=0.1179\end{array}$}} \\
\hline & & & & & & \\
\hline
\end{tabular}

(*) $\mathrm{T}>\mathrm{S}>\mathrm{T}-1 \quad(* *)$ More than 4 waves participating in GSOEP

Dependent Variable: Change in Health Satisfaction between the periods t-1 and $t$

Model A.1: No interaction effects. Model A.2: Interaction effects 
Table 8. Model A: Random effects estimations. Years: 1984-2001. Women

\begin{tabular}{|c|c|c|c|c|c|c|}
\hline & \multicolumn{3}{|c|}{ MODEL A.1 } & \multicolumn{3}{|c|}{ MODEL A.2 } \\
\hline & Coeff. & & St.Errors & Coeff. & & St.Errors \\
\hline Cons. & 5.452 & $* * * *$ & $(0.072)$ & 4.198 & $* * * *$ & $(0.057)$ \\
\hline H. Satisf. T-1 & -0.629 & $* * * *$ & $(0.006)$ & -0.606 & $* * * *$ & $(0.007)$ \\
\hline Change HH Inc. $(<0=1)$ & -0.044 & $* *$ & $(0.022)$ & -0.096 & $* * *$ & $(0.028)$ \\
\hline Age T-1 & -0.028 & $* * * *$ & $(0.001)$ & & & \\
\hline Not German=1 & -0.202 & $* * * *$ & $(0.036)$ & -0.270 & $* * * *$ & $(0.045)$ \\
\hline East German $=1$ & -0.182 & $* * * *$ & $(0.033)$ & -0.220 & $* * * *$ & $(0.041)$ \\
\hline Job Loss $\mathrm{S}(*)$ & -0.099 & & $(0.064)$ & & & \\
\hline Long Participation (**) & -0.021 & & $(0.023)$ & -0.097 & $* * * *$ & $(0.026)$ \\
\hline Job Loss $*$ Age $(>50=1)$ & & & & -0.791 & $* * * *$ & $(0.191)$ \\
\hline Job Loss*Children & & & & -0.192 & & $(0.167)$ \\
\hline Job Loss*High Education & & & & 0.198 & & $(0.146)$ \\
\hline \multirow[t]{4}{*}{ Job Loss*Main Earner (T-1) } & & & & -0.048 & & $(0.234)$ \\
\hline & \multicolumn{3}{|c|}{$\mathrm{N}=26.915$} & $\mathrm{~N}=17.0$ & \multicolumn{2}{|c|}{$\mathrm{N}=17.0177$} \\
\hline & \multicolumn{3}{|c|}{ Wald chi $2(7)=12,544.37 * * * *$} & \multirow{2}{*}{\multicolumn{3}{|c|}{$\begin{array}{l}\text { Wald } \operatorname{chi} 2(9)=7,416.32 * * * * \\
\text { Rho }=0.1316\end{array}$}} \\
\hline & \multicolumn{3}{|c|}{ Rho $=0.1323$} & & & \\
\hline
\end{tabular}

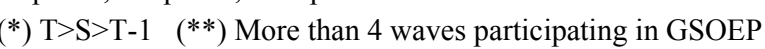
Source: GSOEP

Dependent Variable: Change in Health Satisfaction between the periods t-1 and $t$

Model A.1: No interaction effects. Model A.2: Interaction effects 
Table 9. Model B: Random effects estimations. Years: 1984-2001. Men.

\begin{tabular}{|c|c|c|c|c|c|c|}
\hline ne & \multicolumn{3}{|c|}{ MODEL B.1 } & \multicolumn{3}{|c|}{ MODEL B.2 } \\
\hline & $\overline{\text { Coeff. }}$ & & St.Errors & Coeff. & & St.Errors \\
\hline Cons. & 6.608 & $* * * *$ & $(0.140)$ & 4.950 & $* * * *$ & $(0.082)$ \\
\hline H. Satisf. T-3 & -0.751 & $* * * *$ & $(0.009)$ & -0.734 & $* * * *$ & $(0.010)$ \\
\hline Change HH Inc. $(<0=1)$ & -0.101 & $* * *$ & $(0.037)$ & -0.153 & $* * * *$ & $(0.039)$ \\
\hline Age T-3 & -0.037 & $* * * *$ & $(0.003)$ & & & \\
\hline Not German=1 & 0.028 & & $(0.063)$ & -0.003 & & $(0.064)$ \\
\hline East German $=1$ & -0.124 & & $(0.068)$ & -0.115 & & $(0.070)$ \\
\hline Job Loss S1(*) & -0.600 & $* *$ & $(0.242)$ & & & \\
\hline Job Loss S2(**) & -0.303 & & $(0.176)$ & & & \\
\hline Job Loss S3(***) & -0.448 & $* * *$ & $(0.129)$ & & & \\
\hline Long Participation $(* * * *)$ & 0.044 & & $(0.038)$ & -0.049 & & $(0.039)$ \\
\hline Job Loss $(\mathrm{S} 3)^{*}$ Age $(>50=1)$ & & & & -0.902 & $* * *$ & $(0.283)$ \\
\hline Job Loss (S3)*Children & & & & -0.657 & $* *$ & $(0.265)$ \\
\hline Job Loss (S3)*High Education & & & & 0.090 & & $(0.272)$ \\
\hline \multirow[t]{4}{*}{ Job Loss (S3)*Main Earner (T-3) } & & & & 0.469 & r & $(0.283)$ \\
\hline & \multicolumn{3}{|c|}{$\mathrm{N}=10.816$} & \multicolumn{3}{|c|}{$\mathrm{N}=10.239$} \\
\hline & \multicolumn{3}{|c|}{ Wald chi2 $(9)=6,587.92 * * * *$} & \multicolumn{3}{|c|}{ Wald $\operatorname{chi} 2(9)=5,957.17 * * * *$} \\
\hline & \multicolumn{3}{|c|}{$\mathrm{Rho}=0.3428$} & \multicolumn{3}{|c|}{$\mathrm{Rho}=0.3345$} \\
\hline
\end{tabular}

$(*) \mathrm{T}>\mathrm{S} 3>\mathrm{T}-1(* *) \mathrm{T}-1>\mathrm{S} 2>\mathrm{T}-2(* * *) \mathrm{T}-2>\mathrm{S} 1>\mathrm{T}-3(* * * *)$ More than 4 waves participating in GSOEP Source: GSOEP

Dependent Variable: Change in Health Satisfaction between the periods $t-3$ and $t$

Model B.1: No interaction effects. Model B.2: Interaction effects 
Table 10. Model B: Random effects estimations. Years: 1984-2001. Women.

\begin{tabular}{|c|c|c|c|c|c|c|}
\hline & & $M O D$ & & & $M O D$ & \\
\hline & Coeff. & & St.Errors & Coeff. & & St.Errors \\
\hline Cons. & 6.511 & $* * * *$ & $(0.181)$ & 5.040 & $* * * *$ & $(0.109)$ \\
\hline H. Satisf. T-3 & -0.745 & $* * * *$ & $(0.012)$ & -0.735 & $* * * *$ & $(0.013)$ \\
\hline Change HH Inc. $(<0=1)$ & -0.068 & & $(0.050)$ & -0.120 & $* *$ & $(0.052)$ \\
\hline Age T-3 & -0.036 & $* * * *$ & $(0.004)$ & & & \\
\hline Not German=1 & -0.250 & $* * *$ & $(0.086)$ & -0.325 & $* * * *$ & $(0.089)$ \\
\hline East German=1 & -0.118 & & $(0.077)$ & -0.121 & & $(0.080)$ \\
\hline Job Loss S1(*) & -0.912 & $* * *$ & $(0.292)$ & & & \\
\hline Job Loss S2(**) & -0.150 & & $(0.224)$ & & & \\
\hline Job Loss S3(***) & -0.319 & & $(0.182)$ & & & \\
\hline Long Participation $(* * * *)$ & -0.053 & & $(0.051)$ & -0.147 & $* * *$ & $(0.053)$ \\
\hline Job Loss $(\mathrm{S} 3)^{*}$ Age $(>50=1)$ & & & & -1.110 & & $(0.616)$ \\
\hline Job Loss (S3)*Children & & & & -0.563 & & $(0.880)$ \\
\hline Job Loss (S3)*High Education & & & & -0.096 & & $(0.681)$ \\
\hline Job Loss (S3)*Main Earner (T-3) & & & & 0.269 & & $(0.747)$ \\
\hline & $\mathrm{N}=5,97$ & & & $\mathrm{~N}=5,57$ & & \\
\hline & Wald cl & $=3,63$ & $* * * *$ & Wald cl & $=3,28$ & $* * * *$ \\
\hline & $\mathrm{Rho}=0$. & & & $\mathrm{Rho}=0$. & & \\
\hline
\end{tabular}

$(*) \mathrm{T}>\mathrm{S} 3>\mathrm{T}-1(* *) \mathrm{T}-1>\mathrm{S} 2>\mathrm{T}-2(* * *) \mathrm{T}-2>\mathrm{S} 1>\mathrm{T}-3(* * * *))$ More than 4 waves participating in GSOEP

Dependent Variable: Change in Health Satisfaction between the periods $\mathrm{t}-3$ and $\mathrm{t}$

Model B.1: No interaction effects. Model B.2: Interaction effects 
Table 11. Model C: Random effects estimations. Years: 1984-2001. Men.

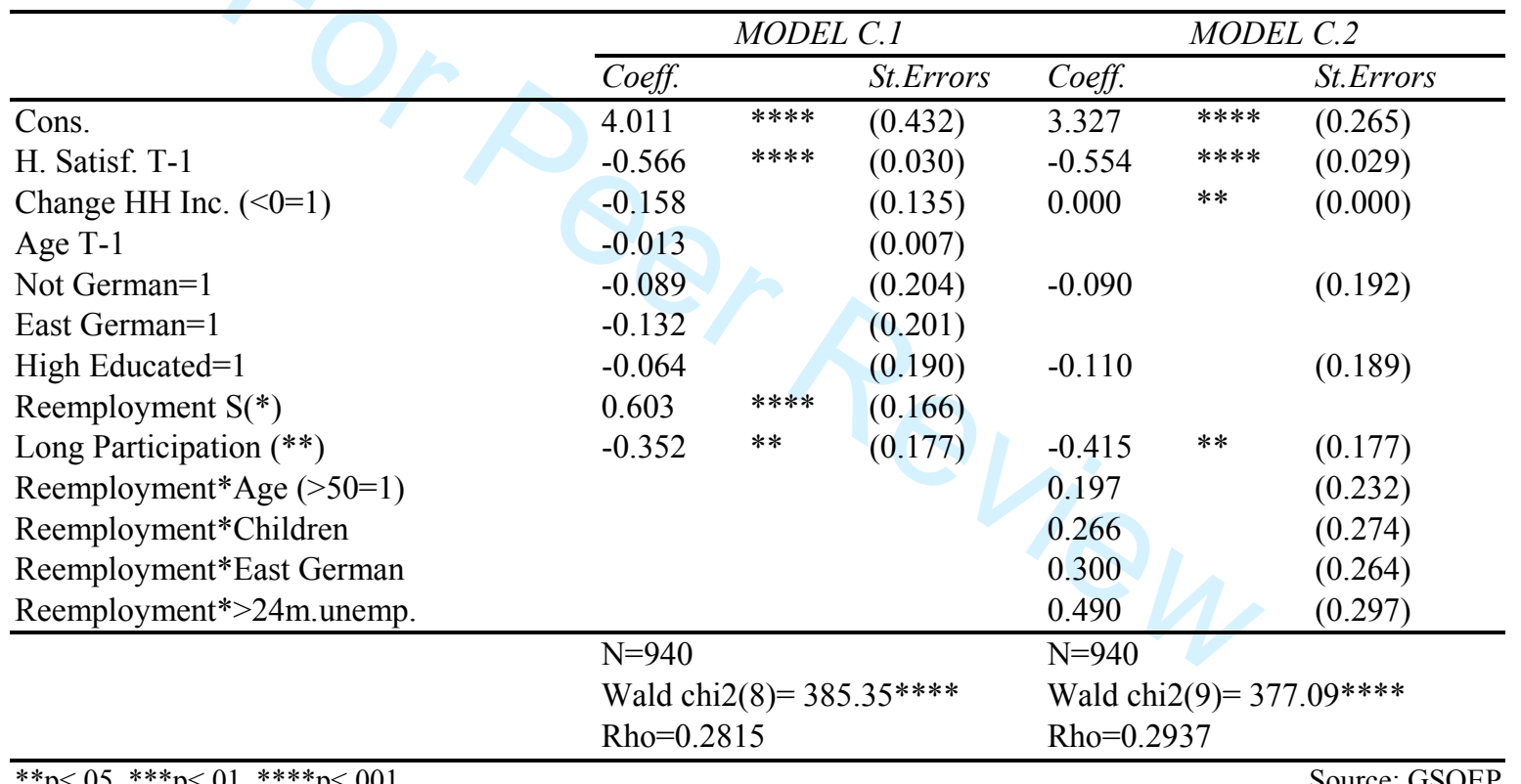

$(*) \mathrm{T}>\mathrm{S}>\mathrm{T}-1 \quad(* *)$ More than 4 waves participating in GSOEP

Dependent Variable: Change in Health Satisfaction between the periods $t-1$ and $t$

Model C.1: No interaction effects. Model C.2: Interaction effects 
Table 12. Model C: Random effects estimations. Years: 1984-2001. Women.

\begin{tabular}{|c|c|c|c|c|c|c|}
\hline & \multicolumn{3}{|c|}{ MODEL C.I } & \multicolumn{3}{|c|}{ MODEL C.2 } \\
\hline & Coeff. & & St.Errors & Coeff. & & St.Errors \\
\hline Cons. & 5.122 & $* * * *$ & $(0.473)$ & 3.008 & $* * * *$ & $(0.253)$ \\
\hline H. Satisf. T-1 & -0.651 & $* * * *$ & $(0.032)$ & -0.607 & $* * * *$ & $(0.031)$ \\
\hline Change HH Inc. $(<0=1)$ & 0.086 & & $(0.129)$ & 0.000 & & $(0.000)$ \\
\hline Age $\mathrm{T}-1$ & -0.042 & $* * * *$ & $(0.007)$ & & & \\
\hline Not German=1 & 0.298 & & $(0.226)$ & 0.330 & & $(0.214)$ \\
\hline East German=1 & -0.095 & & $(0.191)$ & & & \\
\hline High Educated=1 & 0.471 & $* *$ & $(0.197)$ & 0.549 & $* * *$ & $(0.200)$ \\
\hline Reemployment S(*) & 0.532 & $* * * *$ & $(0.146)$ & & & \\
\hline Long Participation $(* *)$ & 0.342 & $* *$ & $(0.166)$ & 0.183 & & $(0.170)$ \\
\hline Reemployment*Age $(>50=1)$ & & & & -0.177 & & $(0.317)$ \\
\hline Reemployment*Children & & & & 0.547 & $* *$ & $(0.238)$ \\
\hline Reemployment*East German & & & & 0.121 & & $(0.244)$ \\
\hline \multirow[t]{4}{*}{ Reemployment*>24m.unemp. } & & & & 0.344 & & $(0.276)$ \\
\hline & \multicolumn{3}{|c|}{$\mathrm{N}=860$} & \multirow{2}{*}{\multicolumn{3}{|c|}{$\begin{array}{l}\mathrm{N}=860 \\
\text { Wald } \operatorname{chi} 2(9)=389.09 * * * *\end{array}$}} \\
\hline & \multicolumn{3}{|c|}{ Wald $\operatorname{chi} 2(8)=443.88 * * * *$} & & & \\
\hline & \multicolumn{3}{|c|}{$\mathrm{Rho}=0.3537$} & \multicolumn{3}{|c|}{$\mathrm{Rho}=0.3748$} \\
\hline
\end{tabular}

(*) $\mathrm{T}>\mathrm{S}>\mathrm{T}-1 \quad(* *)$ More than 4 waves participating in GSOEP

Dependent Variable: Change in Health Satisfaction between the periods $\mathrm{t}-1$ and $\mathrm{t}$

Model C.1: No interaction effects. Model C.2: Interaction effects 